\title{
EFFICACY OF THE PARTNERSHIP BETWEEN TEACHER EDUCATION INSTITUTIONS AND PRIMARY SCHOOLS IN TEACHER PREPARATION IN ZIMBABWE
}

\section{S. Magudu}

School of Education

Great Zimbabwe University

Zimbabwe

e-mail: srmagudu@yahoo.com.au

\section{M.T. Gumbo}

Department of Science and Technology Education

University of South Africa Muckleneuk Campus

Pretoria, South Africa

e-mail: gumbomt@unisa.ac.za

\section{ABSTRACT}

The purpose of this generic, qualitative study was to examine the efficacy of teacher education institutions (TEls) and schools in Zimbabwe, in regard to partnering for the delivery of teacher education. Data were collected through semi-structured interviews and a focus group discussion (FGD) involving 24 participants comprising student teachers, college lecturers and mentors. The findings revealed that there was a framework for TEl-schools collaboration in teacher preparation. The efficacy of the partnership was, however, undermined by such factors as the inadequate attention accorded to various aspects deemed central to effective partnerships, such as planning, mentoring, TEI visits to schools, communication and inconsistencies that seemed to characterise the relationship. The findings suggest that the efficacy of the partnership can be enhanced by recognising the interdependent nature of the relationship, the diversification of areas of TEIschools joint activity, and increased conversations between the partners about issues which are pertinent to the arrangement. The knowledge derived from the study may provide insights into factors that contribute to undermining the effectiveness of partnerships, as well as the implications of these for the professional development of prospective teachers.

Keywords: efficacy, field experiences, partnership, primary schools, student teachers, teacher education institutions, teacher preparation

\section{INTRODUCTION}

Teacher education institutions (TEIs) and schools have traditionally been the main sites of teacher learning. This relationship between the key players in teacher education, though central in defining the outcomes of initial teacher education (ITE) (Brisard, Menter and Smith 2005), 
has often been considered lacking and superficial, especially in terms of integrating knowledge from both educational settings (Smedley 2001). The search for teacher education models that enhance teacher effectiveness (and, ultimately, teacher quality) has resulted in the emergence of what are primarily practical approaches which accentuate the role of field experiences in the process of learning to teach. Such approaches have necessitated the increased involvement of schools in teacher preparation, and closer collaboration between TEIs and schools, thus making TEI-schools partnerships a common trend in ITE.

Consistent with the above trend, the research revealed the emergence of a variety of models of primary teacher education in the sub-Saharan context, which call for TEI-schools partnerships (Mattson 2006). Countries in this context, such as Zambia, Malawi, Ghana, the Gambia and Zimbabwe, have adopted teacher education programmes with substantial schoolsbased components, and which require extended school internships during aspiring teachers' initial training. A partnership between TEIs and schools in teacher preparation appears to be a practical option for these countries. In Zimbabwe, each year thousands of student teachers who are studying towards a Diploma in Education are deployed into primary schools for extended field experience. This requires TEIs and schools to work together closely in respect of teacher preparation. The question, though, relates to the effectiveness of such collaboration (Mudavanhu 2014; Ndlovu 1993). The situation has not been helped by a dearth of research into how well the arrangement is working. Most studies on teacher education in Zimbabwe tend to focus on one aspect of the partnership, namely mentoring (Chiromo 1999; Maphosa, Shumba and Shumba 2007; Mtetwa and Thompson 2000; Tirivanhu 2014), rather than a holistic examination of the concept. Consequently, any reference to issues of partnership has usually emerged as part of the recommendations of other studies, whose focus was not primarily on collaboration in teacher preparation (Magudu 2014; Ndlovu 1993). The focus of this article is therefore on the direct, day-to-day workings of the TEI-schools partnership, in an attempt to examine its efficacy in delivering teacher education in terms of the nature, scope and coherence of the partnership, and the challenges emerging in the course of such collaboration. The contribution of this study is in documenting and seeking to understand the workings of the concept of TEI-school partnerships, as it relates to Zimbabwe. The study also seeks to provoke stakeholders to reflect on the partnership and to provide a framework for future research, since there is scant literature on the subject.

\section{BACKGROUND: TEI-SCHOOLS PARTNERSHIP IN ZIMBABWE}

In Zimbabwe, the notion of a TEI-schools partnership in teacher education has evolved over years. For example, since the 1980s, various models for training primary teachers have been 
adopted. Such models include a three-year "conventional" programme (3-3-3 programme, which refers to its structuring, which sees prospective teachers spend three terms at college doing the theoretical aspects of the course, three terms on field experience, and the last three terms back at college). The "conventional" programme was offered by the majority of primary teachers' colleges, and trainees spent two-thirds of the training period at college learning theory and the remaining third on teaching practice (TP) in schools. This programme has been criticised in educational circles for producing highly theoretical practitioners who experienced shorter periods of integrating theory with practice.

The other model was the Zimbabwe Integrated Teacher Education Course (ZINTEC), introduced at four selected teachers' colleges. Its adoption was driven by the need to address the problem of teacher shortages, created by the rapid expansion of primary education postindependence. The ZINTEC model entailed trainees spending extended periods of training (about $66 \%$ of the four-year programme) on field experience, thus implying some form of school-centred (on-the-job) training. But the student teachers, as was the case with the 3-3-3 programme, were required to assume full responsibility for teaching classes, without the support of a class teacher or mentor, and with only school heads playing a role in assessing trainees.

In the mid-1990s, as it became apparent that the problem of teacher shortages had been addressed, there was a shift from a concern with teacher quantity to that of enhancing teacher quality (Bourdillon 2000). Hence, from 1995 all primary teacher training colleges in the country, including former ZINTEC institutions (the ZINTEC programme having been phased out), adopted the attachment teaching practice model. This model made it mandatory for all student teachers on TP to be assigned experienced teachers as mentors, but did not permit them to take full charge of classes (Chiromo 1999).

Then, in 2002, a modified version of the ZINTEC programme, i.e. 2-5-2 or the Unified Primary Teacher Education model, was introduced. This step came as a result of the recurrence of teacher shortages caused by the brain-drain which had been triggered by the economic meltdown of the country. This in-out-in model (which is still operational) extends the teaching practice period to five terms. It is not only meant to balance quantity with quality, but also to enhance the quality of field experiences. In an effort to achieve these goals, student teachers are not required to take responsibility for a class, but are assigned a mentor who is supposed to provide them with professional guidance in the process of learning to teach. The model gives teachers and schools increased responsibility in respect of teacher preparation, thus demanding the nurturing of a culture of collaboration between TEIs and schools.

This article mainly focuses on the collaboration between TEIs and schools (which are the 
institutions on the ground). It should, however, be noted that the partnership in ITE in Zimbabwe is broader than the arrangement between TEIs and schools, as other significant stakeholders in teacher education are involved, including the Ministry of Primary and Secondary Education, the Ministry of Higher and Tertiary Education and the University of Zimbabwe (UZ). Teacher training colleges (also referred to as TEIs in this study) resort under the jurisdiction of the Ministry of Higher and Tertiary Education. Student teachers practise in schools under the Ministry of Primary and Secondary Education, which pays their stipend for the five terms during which they are on practicum in schools. All teacher training colleges are affiliates of UZ, through its Department of Teacher Education (DTE), and by virtue of this, UZ as an institution influences policy on teacher preparation. Since all primary teachers' colleges in the country offer a similar Diploma in Education programme, from the same awarding institution, in this study we consider the association between TEIs or teacher training colleges and primary schools to be a single entity. This explains why reference is made to a "partnership" rather than "partnerships".

\section{CONCEPTUAL FRAMEWORK}

Partnerships in teacher education generally evolved in response to concerns about the quality of student teachers' professional learning experiences while participating in pre-service teacher education programmes, which seemed to be provided out of context. These traditional programmes were characterised by a rigid separation between Higher Education Institution (HEI) programmes and in-school experiences into different and loosely linked schemes, i.e. viewing HEI academic knowledge as the only authoritative source on teaching (Brisard, Menter and Smith 2005; Zeichner 2010), and the overemphasis on academic competence in the preparation of teachers (Sultana 2005), resulting in a disengagement (or lack of linkages) between subject matter and teaching processes (Bezzina and Van Velzen 2006; Sultana 2005).

The term "partnership" is used to describe the different models of collaboration and cooperation between HEIs or TEIs and schools, in an endeavour to provide quality initial teacher training (ITT) experiences for teacher-trainees (Dhillon 2009; Lynch and Smith 2012; Moyles and Stuart 2003). Partnerships therefore represent an innovation in teacher preparation and a departure from the traditional conceptualisation of ITE, to what Zeichner $(2010,89)$ describes as "a new epistemology for teacher education where there is a non-hierarchical interplay between academic, practitioner and community expertise". A consequence of such an approach would be the creation of hybrid spaces (Zeichner 2010) or a "third space" in teacher education, "which is separate from the culture of either institution and allows for more creative ways of working together" (Greany and Brown 2015, 14). According to Flessner (2014), this 
third space also recognises binaries and creates new spaces for reflection and renewal.

The literature identifies three main types of partnership, namely collaborative, complementary and HEI-led (Brooks 2006; Cunningham 2012). These different forms of partnership generally have the common purpose of enabling stakeholders in teacher education to work together, and share the responsibilities and goals of teacher preparation and professional development (Ducharme and Ducharme 1993). Other key goals of partnerships, as cited in the literature, include

- "developing a shared understanding of the purposes, processes and intended outcomes of student teaching experiences" (Ducharme and Ducharme 1993, 18);

- "facilitating the achievement of a more coherent and integrated approach to teacher education" (European Commission Directorate-General of Education and Culture 2010) "through synergising its various components (i.e. the theory and subject matter provided by TEIs and practice in schools)" (Bezzina and Van Velzen 2006; Sultana 2005); and

- "providing authentic and expanded professional learning experiences for pre-service teachers, by enabling them to learn in and from practice" (Feiman-Nemser 2001).

These goals underline Eraut's (1994) contention that professional learning is a product of both propositional (theoretical aspects) and procedural (practical elements) knowledge. Thus, this goal emphasises the significance of partnerships in teacher preparation, as these elements of knowledge are acquired at two sites respectively, namely training colleges and schools.

Scholars concur that the idea of a partnership implies that certain direct benefits should accrue to all parties involved. The benefits for trainees are the development of professional competence and confidence (Moyles and Stuart 2003, 1); being equipped to perform complex teaching tasks (Zeichner 2010), and being prepared for diverse school situations. On the other hand, for TEIs and schools, the rewards of collaboration include bringing together different yet complementary experts and facilitating the sharing of perceptions, beliefs and practices (Bullock and Scott 1995; Smedley 2001); extending knowledge about teaching and learning through research (European Commission Directorate-General of Education and Culture 2010); and addressing recruitment and teacher shortages (Cunningham 2012).

The literature does, however, indicate that the success of partnerships is dependent on several essential elements, such as shared goals, trust between partners, clear channels of communication and each partner keeping the other informed (Billett, Ovens, Clemans and Seddon 2007; Ducharme and Ducharme 1993). Other factors which could affect the success of a partnership are the extent to which the collaboration is positive and empowering, as well as reciprocal (with all partners benefitting from the arrangement) (Cunningham 2012); it ensures the equality of all voices (in schools and among TEI staff); accommodates practitioner priorities 
and knowledge, and acknowledges the "mind gap" or cultural differences between TEIs and schools (Greany and Brown 2015); and the manner in which issues of power and control are handled (Greany and Brown 2015). In a nutshell, partnerships in teacher education call for a reexamination and redefinition of traditional roles. But, as observed by Zeichner (1992, in Ducharme and Ducharme 1993), working out the new dimensions of their roles is a difficult task for TEIs, teachers and school administrators. The formation and implementation of effective working partnerships remains a challenging yet elusive goal (Billett et al. 2007; Brooks 2006; Greany and Brown 2015).

\section{RESEARCH METHODOLOGY}

This study adopted a generic, qualitative research approach to examine the efficacy of the partnership between TEIs and schools, in respect of teacher preparation. According to Caelli, Ray and Mill (2003, 2), a generic qualitative study is not "guided by any specific or established set of philosophical assumptions in the form of one (or more) established qualitative methodologies", such as grounded theory, phenomenography or ethnography. Its main purpose is to locate and understand a phenomenon or process, or the perspectives and worldviews of those involved (Merriam cited in Caelli et al. 2003, 2). Scholars concur on the practicality of the generic approach, but caution that its credibility can be undermined by a lack of rigour and a limited grasp of qualitative research (Caelli et al. 2003; Cooper and Endacott 2007; Kahlke 2014), hence the need to pay particular attention to these aspects.

Purposive sampling was employed to identify participants in the study, as the focus was more on understanding than on generalisability, and on working with participants who would cede rich and thick data (Creswell 2007). The sample consisted of 24 participants - six student teachers, nine mentors (four of whom were either school heads or deputies) and nine college lecturers (who included a TP coordinator for each participating TEI). Three rural schools were targeted, which hosted the student teachers and resorted under the same cluster. Rural schools were preferred, since this is where the majority of the country's inhabitants are located and where most prospective teachers would therefore be deployed.

The school heads of participating schools were asked to provide a list of student teachers they hosted, as well as their parent TEIs. Using this list, the participating TEIs and two student teachers from each were identified. The student teachers, who were in their final term of teaching practice, were thus in a position to reflect on their experiences of practicum. Three lecturers were drawn from each participating TEI, along with three mentors from each school. The main demographic variable considered for lecturers and mentors was experience with issues pertaining to the TEI-schools' relationship. The lecturers had an average of eight years' 
experience as teacher educators, and were therefore conversant with issues of TEI-schools' collaboration. The mentors were seasoned teachers, with teaching experience ranging from eight to 15 years. In addition, they had previously participated in mentoring trainee teachers. The inclusion of school heads or deputies was crucial, as they would be central to the forging of the partnership. These different categories of participants represented the key stakeholders in the partnership, with their multiple perspectives providing rich and sufficient data central to understanding the complexities of that partnership and accounting for all aspects of the phenomenon (Morse et al. 2002).

After identifying potential research sites, permission was sought from the relevant authorities to conduct the research. Informed consent was also obtained from the participants prior to commencing data collection. To that effect, participants were provided with consent forms which highlighted such aspects as the purpose, procedures, risks and benefits of the study.

Data were collected through individual, semi-structured interviews with lecturers and mentors, and a focus group discussion with student teachers. The focus group session was conducted at a school located within the cluster. Preliminary visits were made to participating schools, to make arrangements for the interviews and focus group session. The focus group interview questions were open ended, which enabled the researchers to appraise the quality, coherence and limitations of the partnership, and to triangulate the data. The information from each interview was later summarised and made available to the participants for validation. Member-checking and triangulation were pertinent in ensuring the trustworthiness of the study.

The thematic approach was used to analyse the data, for its flexibility in terms of use (Braun and Clarke 2006). The process of analysis involved searching through the data to identify recurring issues or patterns of meaning (Braun and Clarke 2006), after which the data were reorganised according to the identified themes.

\section{FINDINGS AND DISCUSSION}

The findings are arranged around the three main themes, which form the basis for examining the efficacy of the partnership: understanding the notion of the partnership, the operationalisation of the partnership, and paradoxes pertaining to the partnership.

\section{Understanding the notion of a partnership}

This theme examined participants' understanding of the concept of a partnership, and solicited their views about the envisaged benefits of such an arrangement. Both TEI lecturers and mentors voiced appreciation for the concept of a partnership. Schools broadly viewed the purpose of the partnership as being to assist the student teachers in becoming wholesome 
teachers. On the other hand, lecturers described the goals of collaboration as being

"to bring TEIs and schools together to work as partners in the development of professional teachers ... in the making process so that the receiving end [schools] won't play the blame game when the end product has some gaps".

These views imply that the partners were aware of their shared responsibility in respect of teacher preparation. In addition, the participants appreciated the benefits that could accrue to them from collaborating in ITE. The benefits cited for the trainees were that they would be granted an opportunity to apply the theory learned at college, rather than having a lot of theory which at times is obsolete, and that they would have the real picture and feel of the profession. Schools anticipated such benefits as

- " "having the chance to participate in the making of the products that will finally serve us ..."

- "revitalisation in terms of new educational ideas and knowledge ..."

- "a reduction in workload in the classroom and in co-curricular activities".

For TEIs, collaboration with schools would enable them to keep abreast with what is prevailing in the sister ministry [the Ministry of Primary and Secondary Education] as well in schools, both of which will eventually absorb the new teachers. All these potential benefits would result in what one lecturer termed $a$ win-win situation. A shared purpose and mutual investment were pertinent in providing a positive basis for the partnership.

\section{Operationalisation of the partnership}

This category encompasses the placement of student teachers for TP, a delineation of their roles and responsibilities, and the specific responsibilities of the partners (such as supervision and assessment, mentoring and TEI visits, and mutual communication). These are some of the elements that Cunningham (2012) identifies as indicating the extent to which schools and TEIs have developed an effective partnership "in practice". The other indicators identified by the same author relate to planning, documentation, content, the contractual relationship and legitimation.

\section{Placement}

Lecturers indicated that their institutions deployed students to an average of 200 schools each (per college), and that the host schools were scattered over wide geographical areas, mainly within the provinces where the TEIs are located. The criteria used to identify schools for student 
teaching placements usually included the availability of qualified and experienced teachers, accessibility of the schools and their capacity to provide accommodation for the trainees. The above criteria, however, were not always adhered to, as it would appear that in practice TEIs mostly settled for any school that was willing to host student teachers, those that requested for students or trainees' own local schools identified by students themselves. This suggests that the identification of host schools was unsystematic and determined by expedience. Such a situation, combined with the involvement of a large number of schools in student teacher placements, might have made it difficult for TEIs to ensure that the selected settings were able to model the desired teaching practices and that they could forge meaningful relationships with each host school (Darling-Hammond 2002).

\section{Delineation of roles and responsibilities}

The roles and responsibilities of schools were outlined in the information packages that TEIs provided on the deployment of student teachers. Typical packages contained

"guidelines on mentoring, supervision and assessment of the student teacher and teaching load; college policy documents and formats for planning for instruction; assessment instruments; DTE criteria for assessment".

The tasks of schools, as specified in the information packages, were to carry out school-based supervision and assessment of student teachers; produce reports; conduct book inspection; provide mentors, professional guidance and counselling of student teachers; as well as to induct students on school and community ethos. These specifications regarding the responsibilities of schools were meant to facilitate better planning and time management in support of student teachers (Moyles and Stuart 2003). In a way, they also reflected the contractual relationship between the partners (Furlong, cited in Cunningham 2012).

\section{Mentoring}

The TEI guidelines specified that student teachers had to be assigned mentors. The responsibilities of the mentors, from the perspective of the lecturers, were to be role models, critical friends and to mould the student teachers on issues of pedagogy and classroom management. Similarly, mentors described their role as follows:

- "To be the chief trainers of the student teachers since we know what is required by the school and by the ministry ..."

- "to supervise student teachers' work ..."

- "to assess them using the instrument provided by the college". 
The above excerpts suggest that TEIs and schools had a shared understanding of the mentors' responsibilities. Despite an awareness of the significance of mentoring in the TEI-schools' partnership, the partners might not have accorded due attention to aspects that were central to effective mentoring, such as investment in mentor selection, preparation and support (Menter, Hulme, Elliot and Lewin 2010). The task of selecting mentors was left to schools on the basis that they know their teachers best. TEIs, though, specified that teachers who were assigned mentoring roles should be qualified and experienced, and in addition, discouraged school heads, deputy heads and TICs from mentoring students. But indications were that in some instances, schools attached trainees to senior teachers who have extra responsibilities so that when they are busy with these other duties, the student teacher can take over responsibility for the class. Lecturers viewed such an arrangement negatively, since trainees would be required to take on full teaching loads, which they described as equivalent to employing trainees as relief teachers.

Other instances of problematic mentor allocation, as highlighted by the student teachers, included being assigned (by design or default) a mentor who was enrolled for part-time studies and who could take advantage of the presence of a trainee to concentrate on their studies and overload the trainee with responsibilities or being attached to a mentor who was on leave, implying that the trainee would again take full responsibility of a class. Such arrangements would have denied student teachers access to those models of good practice that learning in and from practice should facilitate (Burn and Mutton 2013; Feiman-Nemser 2001). One mentor, though, argued that it was not always possible to adhere to TEI specifications on mentoring and that, at times, schools were compelled to advise colleges that what [they] require may derail [existing] programmes in the school. This implies that schools had other mandates that needed attention, and this presented a dilemma in terms of how to accommodate the priorities of various roleplayers in a partnership (Greany and Brown 2015). It also raised questions about schools' sense of responsibility for ITE.

The literature identifies mentor training as an important factor in TEI-school collaboration (Zeichner 2010). Indications are, however, that this aspect might have been overlooked, as explained by one mentor:

"There is no training as such but some of the teachers who are mentors have been mentored by other teachers and they know how they were mentored and can use that knowledge to assist the student teachers."

Such an arrangement would imply leaving things to chance. However, lecturers made reference 
to TEIs communicating the responsibilities of mentors through handouts given to students as they go on TP and guidelines by the college, and claimed that TEIs occasionally conduct workshops and seminars with mentors, where TP issues are discussed as part of preparing them for their role. But a mentor disputed the comment pertaining to the holding of workshops and insisted that colleges do not conduct workshops and instead schools and clusters sometimes run workshops on mentor-student teacher relationships and how to assess the student teachers. The lack of preparation and support of schools-based supervisors in terms of equipping them with the requisite knowledge and skills to manage mentoring relationships was a dichotomy, for without the necessary knowledge and skills they would be unable to implement a more active and educative concept of mentoring.

As for the actual mentoring, some student teachers indicated that they benefitted from the process and described their mentors as supportive. They alluded to mentors demonstrating [how] to teach, assisting with marking and sourcing of media, indicating that they received some support. Most trainees, however, reported a reluctance by certain mentors to allow them opportunities to participate in key tasks in the classroom, since they generally considered the presence of student teachers to be an inconvenience, as explained in the following composite excerpt:

\footnotetext{
"It was like you are delaying them [mentors] by what you were doing ..."

"the mentor during TP was eager to do all the activities, giving work, marking, so the student teacher will just sit ..."

"I lack test setting because we were not setting tests during TP ..."

"the mentor only allowed me to mark written work in mathematics and not compositions, so I don't know how to mark compositions".
}

Other inconsistencies in terms of mentoring that the participants alluded to were the following: after a student teacher had prepared for a specific lesson, a mentor could decide just before its delivery: this is not what I want you to teach today, and then assign the teacher-trainee a new task, or assign him/her to teach content subjects such as Social Studies or Religious and Moral Education, which mentors were not comfortable with, and do not form part of the core curriculum. All these practices might have been a reflection of a limited understanding, by mentors, of the purposes, processes and intended outcomes of the student teaching experience (Ducharme and Ducharme 1993). Furthermore, the failure by schools (mentors) to deliver adequate opportunities for practise would have undermined the development of professional competencies and confidence in the prospective teachers (Moyles and Stuart 2003), and defeated the purpose of the extended field experiences and training in context. 
The mentors provided several explanations for the above practices, referring to, among others, the trainees' limited teaching skills:

"A mentor might be forced to take over a lesson that a student teacher was supposed to teach after realising that the student teacher is struggling, is not capable of teaching and is 'killing' my class."

Furthermore, a number of mentors were of the view that some student teachers are lazy, they make excuses about having a lot work and this makes it difficult for a mentor to closely monitor them. In the situations described above, mentors who emphasised that they were the owners of the classes in which the trainees were practising (and were ultimately accountable for their performance, which would be reflected in the term-on-term rankings of classes), found it necessary to do most of the teaching. Some lecturers, however, attributed the seeming lack of commitment to their duty towards student teachers to the fact that mentors were not rewarded for the additional workload. They argued that as mentors they feel used if unpaid for their services, and would perform better if they are incentivised. This introduced the dimension of how to motivate the mentors, or to give them recognition to encourage them to commit to their role (Hobson 2002) - an issue that does not seem to have been catered for in the partnership agreement.

\section{Supervision and assessment}

The supervision and assessment of student teachers were the responsibility of both TEI lecturers and school-based supervisors (mentors and administrators), who were supposed to observe the student teachers' lessons and produce written reports. Schools were required to supervise and assess student teachers using a supervision instrument provided by TEIs at least three times a term. Indications were that most TEIs incorporated at least two school-based assessment marks into a computation of a final TP grade for the trainees, thus recognising the input of schools in teacher preparation. However, some lecturers questioned the credibility of the high grades which mentors awarded to student teachers, especially where there were discrepancies in terms of the marks they awarded and those awarded by school-based supervisors. Discrepancies were attributed to such factors as certain schools being generous with marks or a failure by schools to apply the DTE assessment criteria (implying differing understandings of the instrument).

Another possible source of the problem could have been a lack of training for those responsible for assessment in schools (Brooks 2006), as noted earlier. Mentors viewed the lecturers' scepticism about school-based marks as depreciating their contributions and expertise. This is apparent in remarks they made, that some lecturers feel they are superior over 
mentors and this doesn't go well with mentors who feel that they are partners in the making of a teacher and that school-based teacher educators expected their professional perspectives to be respected. Such sentiments suggest underlying tensions between the partners. These possible tensions are illustrated by the manner in which one administrator handled poor performance by trainees, as explained:

"When a student teacher gets repeated adverse reports from college lecturers, we tell the student teacher to follow their lecturers because in this school we expect our teachers to work hard."

The above excerpt might also be an indication of the extent to which schools took ownership of the ITE programme, and points to a need for schools to buy into the idea of being significant stakeholders in teacher education.

\section{TEl school visits}

TEI visits to schools were an important feature of the interaction between the partners. TEI lecturers visited schools to supervise and assess student teachers at least once per term, i.e. every four months. The infrequency of the visits was attributed to the location of schools in remote areas, as well as to resource constraints. A mentor felt that the irregularity of visits left the burden of ensuring that students are well prepared to teach to schools. This was ironic, as schools were not formally prepared for the task. Trainees, on the other hand, indicated that at times the visits were undertaken during end term tests session when it would not be possible to observe them teaching. Furthermore, the visits seemed to be rushed, as reflected in the following description of a typical visit:

"The team meets the school administrator first, gives introductions and purpose of visit and lecturer is then led to the classroom. Lecturer supervises student's teaching in the presence of the mentor. After the lesson the lecturer, mentor and student teacher deliberate on the lesson proceedings, highlighting critical feedback on the general performance of the student. The team leader gives feedback on general performance of all students at that school and bids farewell to the school authorities."

Of note in the above quote are the manifold purposes which such visits serve (Cunningham 2012; Moyle and Stuart 2003). First, is the provision of support and feedback to trainees and the identification of areas of weakness that need attention (Cunningham 2012). Second, is the opportunity for collaboration between the partners that manifests through the involvement of lecturers and mentors in joint lesson observations and post-observation conferences. Furthermore, schools viewed the visits as a forum for dialogue between the partners and a 
chance to trouble-shoot. As explained by one mentor, we discuss and iron out issues which might be problematic at the station. This again underlined the many purposes served by TEI visits to schools. But it should be noted that the visits might not have allowed adequate time to get to know each school, its particular ethos and needs, to demonstrate commitment or build trust in the relationship - all of which are central to a functional partnership (Greany and Brown 2015).

\section{Communication between the partners}

Brisard et al. (2005) cite effective communication as the single-most important factor for the successful functioning of a partnership at any level. The data show that, besides the information packages provided on the deployment of student teachers, additional information on TP issues was occasionally relayed to schools through circulars and periodic letters generated by the TP office and information disseminated by the lecturers during school visits. [The TP office was a common feature of all TEIs, handling communication with schools and students, and any other issues relating to teaching practice; it was viewed by participants as an important communication structure.] Communication was nonetheless characterised by a one-way flow of information, with schools being recipients of information from TEIs. The mentors stressed that the circulars and letters were usually from colleges to schools and not from school to college, and that schools only communicated with TEIs when there [was] a problem with the student teacher, that's when we may decide either to telephone or make a written communication to the [college] principal. What stands out here is the emphasis on referring issues to TEIs for final arbitration, rather than joint decision-making by the partners, which should be a proxy of effective partnership (Billett et al. 2007). The imbalance in communication points to an inequality of voices between the partners, and suggests that TEIs might not have been in touch with those issues affecting schools as they acquitted themselves of their role. One mentor felt that the one-sided nature of the communication was logical:

"I think it becomes a very complex situation whereby every school is given an opportunity to communicate with [the] college. You can imagine each school from each district bringing its own suggestions ... it becomes very difficult."

These views further highlight the complexities of incorporating too many schools in a partnership, and suggest the need to revisit this issue.

Another mode of communication, cited by both TEIs and schools, was the trainees themselves. As one mentor explained: 
"The students are required once a month at the college ... They carry our reports to the college, and when they return, they also feed us back what they will have collected from college pertaining to the execution of our duties. We also ask the students, go and tell your TP office we want this, and the students bring it."

This was confirmed by a lecturer, who indicated that TEIs at times informally learned about the expectations of schools from the students themselves. While this mode of communication might have its merits, the effectiveness of indirect communication is debateable.

TEIs and schools were aware of shortcomings in the communication process. Schools suggested that communication between the partners could be enhanced through continual dialogue and collaborative research, more workshops and seminars to appraise each other o[f] challenges and success stories. TEIs, on the other hand, called for the establishment of open lines of communication in terms of information flow, clarifying each other's roles in the process and periodic feedback reviews. What is apparent from these suggestions are the various pertinent issues that were not being addressed, as a result of limited dialogue between the partners.

\section{Paradoxes pertaining to the partnership}

TEIs and schools generally rated their partnership as good and cordial, yet several inconsistencies and limitations characterised the relationship, as emerged from the participants' narratives. For example, mentors and student teachers reported a mismatch in expectations by TEIs and schools about the format of planning for instruction, which trainees needed to adopt. They pointed out that the separate scheme and plan that TEIs required student teachers on TP to adhere to, in planning for instruction, were not consistent with the practices in schools. There, the document in use was a scheme-cum-plan (a composite document which schools justified on the grounds of reducing teachers' workload). One mentor suggested that colleges should teach student teachers to come up with a scheme-cum-plan, rather than a scheme and a plan (separate entities), because it doesn't apply anywhere. This implies that the document required by schools was not relevant to school contexts. What also emerged from this issue is that contradictory messages were being communicated to trainees.

Other indicators of the limitations of collaboration between the partners could be gleaned from concerns mentors raised about the quality of teacher preparation. For instance, they complained about the absence of basic teaching skills in teacher-trainees on deployment for TP:

Students are not adequately prepared before deployment for TP, most students have problems with planning and even lesson in delivery, they lack confidence and won't teach in your presence. I think too much emphasis is being placed on the preparation of the TP files rather than the practical aspect which is pertinent. 
These narratives could have been an expression of a desire to contribute to conversations about enhancing the ITE programme - something which Husbands (cited in Greany and Brown 2015) views as necessary, as it entails student teachers spending more time in schools during their training. The lecturers were aware of these concerns, but ascribed some of the student teachers' perceived skills deficits to a different source:

"The school curriculum changes are not communicated to colleges. Therefore, some of the subjects taught at college will be out of the curriculum and students will go for TP lacking skills in those areas."

The above quotation indicates an inconceivable discrepancy which may have serious implications for the legitimacy of the teacher education programme. Furthermore, mentors questioned the quality of the Professional Studies course offered by colleges, noting that several student teachers were just raw, unfriendly and lacking in interpersonal skills. Many believed this was because colleges do not give them orientation about how they should relate with fellow teachers in schools. One lecturer dismissed these observations regarding the calibre of student teachers, calling it blame shifting, before urging schools and colleges to avoid the blame game on the shortcomings of the programme. However, these views suggest a trivialisation by TEIs of schools' contributions, and the limited capacity of the partners to collaborate in creating solutions to enhance the quality of aspiring teachers' field experiences.

Another inconsistency was the seemingly dominant TEIs' requirements in respect of their interactions with schools. This was demonstrated by their handling of the scheme-cum-plan issue, cited earlier, as well as their requirements for student teachers majoring in Physical Education, as explained:

"Students who specialise in PE have to introduce sporting activities such as tennis and golf of which the schools may lack the resources. Yet students have to practise what they are being taught, it's a big challenge."

Schools felt that this requirement was not practical, as it did not take into account the resource constraints characterising rural contexts, thus reflecting a failure by TEIs to closely adapt the teacher education curriculum to the reality in schools (European Commission DirectorateGeneral of Education and Culture 2010). It also emerged that TEIs required trainees to participate in college events, e.g. sports, whilst schools expect students to be fully part of the school staff during the whole TP period. Such an arrangement was likely to create a dilemma for the student teachers about which instruction to follow. The dominance of TEIs in the 
partnership was again evident in the guidelines on how schools were to handle disciplinary cases involving trainees, whereby schools were expected to refer the cases to them (TEIs) for final adjudication, rather than making provision for joint decisions (which is a proxy of an effective partnership). This ruling reinforces the impression of an unequal relationship. Mentors felt that such an approach influenced some trainees not to respect their role as teacher educators, which means that students will listen more to lecturers than school heads, there is always [a] partner who is more forceful. Hence, schools felt powerless to resolve issues at station level, and would validate even decisions on minor issues such as the dress code by making reference to college requirements, rather than authoritatively imposing their regulations. These reports illustrate the hierarchical nature of the current relationship, the unequal power relations characterising the arrangement, and the limitations that these place on the operationalisation of the partnership.

\section{DISCUSSION AND CONCLUSION}

This study examined the efficacy of the partnership between TEIs and schools in the delivery of teacher education in terms of the nature, scope and coherence of the partnership, and the challenges encountered. The findings show that although there is no formal policy on the TEIschools partnership, there is a framework for collaboration between the key players in teacher education, as evidenced in the appreciation of the potential mutual benefits of the partnership and the delineation of responsibilities. Translating the partnership into practice, however, seemed to present several challenges. What emerges is a limited relationship in which inadequate attention appears to have been paid to various aspects that are central to any effective partnership.

Inadequate emphasis seems to have been accorded to the interdependent nature of the TEIschools relationship in teacher preparation (Bullock and Scott 1995). This was illustrated by the dominance of TEIs in the construction and dissemination of teacher education knowledge and in determining the "terms and conditions" of the partnership. The former seems to have been done without always taking into account the practicalities and relevance of that curriculum in schools, and confirms a hegemony of outside-of-school expertise in respect of teaching and learning. Furthermore, that the partners might have overlooked the nature of their relationship was evident in inconsistencies in expectations TEIs and schools had of each other; the noninvolvement of schools in planning for student placement; the attitudes of lecturers towards discrepancies in grading done by schools; and, generally, in the absence of such proxies of effective partnership as equality of voice between the partners and mechanisms for joint decision making. Schools therefore seemed to be relegated to playing a subordinate role, which 
involves providing a classroom and a mentor, thus merely offering practice fields where student teachers can try out their practices, as recommended or even demanded by the colleges (Moyles and Stuart 2003; Zeichner 2010). These factors would have discounted the idea of the partnership being a collaboration of equals (Wharfe and Burrows 1990) and creating a third space in teacher education.

Schools also seemed to fail to acknowledge the symbiotic nature of the TEIs-schools' relationship, and this was mainly reflected in the manner in which they handled the mentoring of student teachers. Mentoring was clearly the mainstay and "face" of the partnership. But the flawed implementation of the concept of mentoring of student teachers tended to reduce the whole process to a mere formality. Compromises which emerged in the selection of mentors possibly denied student teachers the benefit of learning from models of good practice. In addition, schools and mentors seemed to be reluctant to allow student teachers adequate opportunities to practise their skills, and considered their presence in the classroom to be an inconvenience that could derail our programmes in the school. Such attitudes towards student teachers negate the purpose of extended field experiences. It also means that schools will miss out on an opportunity to participate in shaping a professional teacher according to their own specifications - a teacher who would be ideal for their particular context.

The issues raised above suggest that various aspects relating to the operationalisation of this partnership require revisiting. They reflect a need to diversify the activities which schools and TEIs engage in jointly, to promote the development and strengthening of professional relationships, and capacitate partners so that they collaborate in creating solutions to enhance the quality of teacher education. Such activities could include planning for students' field experiences by undertaking the design and review of the programme cooperatively, through the exchange and sharing of expertise, as well as doing mutually contextually relevant research to improve practice. Furthermore, the data suggest a need to extend the training role of schools and their participation in teacher preparation beyond the provision of field experiences, as a way of acknowledging their expertise. This could be achieved by, for example, involving teachers from partner schools in teaching some of the Professional Studies topics which relate to practical issues. Lastly, schools should be empowered and supported to contribute to teacher education systematically, through mentor training, for instance. Other questions that may require attention relate to enhancing communication between the partners and a commitment to this type of collaboration. All this will work to ensure that student teachers ultimately receive the requisite support during training. 


\section{REFERENCES}

Billett, S., C. Ovens, A. Clemans and T. Seddon. 2007. Collaborative working and contested practices: Forming, developing and sustaining social partnerships in education. Journal of Education Policy 22(6): 637-656.

Bezzina, C. and C. van Velzen. 2006. Partnerships between schools and teacher education institutes. Paper presented at the $31^{\text {st }}$ Association of Teacher Education Conference, Portoroz, Slovenia.

Bourdillon, T. 2000. Education in Zimbabwe: Images of the present as indicators of possible futures. Zimbabwe Journal of Educational Research 12(3): 389-406.

Braun, V. and V. Clarke. 2006. Using thematic analysis in psychology. Qualitative Research in Psychology 3(2): 77-101.

Brisard, E., I. Menter and I. Smith. 2005. Models of partnership of initial teacher education. Full report of a systematic literature review commissioned by the General Teaching Council for Scotland, GTCS Research, Research Publication No. 2. Edinburgh: GTCS.

Brooks, V. 2006. A "quiet revolution"? The impact of training schools in initial teacher training partnerships. Journal of Education for Teaching 32(4): 379-393.

Bullock, K. M. and W. A. H. Scott. 1995. Partnerships in teacher education: A response to the business partnership in school-based/centred initial teacher training. The Vocational Aspect of Education 47(2): 165-176.

Burn, K. and T. Mutton. 2013. Review of "research-informed clinical practice" in initial teacher education. Oxford Review of Education 41(2): 217-233.

Caelli, K., L. Ray and J. Mill. 2003. "Clear as mud": Towards a greater clarity in generic qualitative research. International Journal of Qualitative Methods 2(2): 1-23.

Chiromo, A. 1999. Models of teaching practice since Zimbabwean independence: A critical review. Zimbabwe Bulletin of Teacher Education 8(3): 49-64.

Cooper, S. and R. Endacott. 2007. Generic qualitative research: A design for qualitative research in emergency care? Emergency Medical Journal 24: 816-819.

Creswell, J. 2007. Research design: Qualitative and quantitative approaches. London: Sage.

Cunningham, P. 2012. Moving the debate on partnership in initial teacher education forward: Compromise or innovation? Critical and Reflective Practice in Education 3: 51-61.

Darling-Hammond, L. 2002. How teacher education matters. Journal of Teacher Education 51(3): 166173.

Dhillon, J. K. 2009. The role of social capital in sustaining partnership. British Educational Research Journal 35(5): 687-704.

Ducharme, M. K. and E. R. Ducharme. 1993. School-based teacher education in the United States: An uneven evolution. Australian Journal of Teacher Education 18(2): 15-23.

Eraut, M. R. 1994. Developing professional knowledge and competence. London: Falmer Press.

European Commission Directorate-General for Education and Culture. 2010. Relations between teacher education institutions and schools. Education and Training 2010 programme cluster "Teachers and Trainers". Report of a Peer Learning Activity. Copenhagen, Denmark.

Feiman-Nemser, S. 2001. From preparation to practice: Designing a continuum to strengthen and sustain teaching. Teachers College Record 103(6): 1013-1055.

Flessner, R. 2014. Revisiting reflection: Utilising third spaces in teacher education. Scholarship and Professional Work-Education, Paper 37. http://digitalcommons.butler.edu/coe_papers/37 (Accessed 12 April 2017).

Greany, T. and C. Brown. 2015. Partnerships between teaching schools and universities. Research report. London: London Centre for Leadership in Learning.

Hobson, A. J. 2002. Student teachers' perspectives of school-based mentoring in initial teacher training 
(ITT). Mentoring and Tutoring 10(1): 5-20.

Kahlke, R. M. 2014. Generic qualitative approaches: Pitfalls and benefits of methodological mixology. International Journal of Qualitative Methods 13: 37-52.

Lynch, D. and R. Smith. 2012. Teacher education partnerships: An Australian research-based perspective. Australian Journal of Teacher Education 37(11): 132-146.

Magudu, S. 2014. Induction experiences of newly qualified teachers in Zimbabwe. Unpublished doctoral thesis. Pretoria: University of South Africa.

Maphosa, C., J. Shumba and A. Shumba. 2007. Mentorship for students on teaching practice in Zimbabwe: Are student-teachers getting a raw deal? South African Journal of Higher Education 21(2): 296-307.

Mattson, E. 2006. Field-based models of teacher training. Case studies of student support systems from sub-Saharan Africa. Essex: Department for International Development.

Menter, M., M. Hulme, D. Elliot and J. Lewin. 2010. Literature review on teacher education in the $21^{\text {st }}$ century. Edinburg: Scottish Government.

Morse, J. M., M. Barrett, M. Mayan, K. Olson and J. Spiers. 2002. Verification strategies for establishing reliability and validity in qualitative research. International Journal of Qualitative Methods 1(2): $13-22$.

Moyles. J. and D. Stuart. 2003. Which school-based elements of partnership in initial teacher training in the UK support trainee teachers' professional development? London: EPPI-Centre, Social Science Research Unit, Institute of Education.

Mtetwa, K. J. and J. J. Thompson. 2000. Towards decentralised and more focused school-teacher preparation and professional development in Zimbabwe: The role of mentoring. Journal of InService Education 26(2): 311-328.

Mudavanhu, Y. 2014. The contribution of theory and practice to the professional development of students learning to become secondary teachers in Zimbabwe. Unpublished doctoral thesis. Exeter: University of Exeter.

Ndlovu, T. 1993. The development of a teaching practice curriculum for teacher education in Zimbabwe. Unpublished doctoral thesis. Pretoria: University of South Africa.

Smedley, L. 2001. Impediments to partnership: A literature review of school-university links. Teachers and Teaching: Theory and Practice 7(2): 189-209.

Sultana, R. G. 2005. Initial education of high school teachers: A critical review of major issues and trends. Studying Teacher Education 1(2): 225-243.

Tirivanhu, M. S. 2014. Experiences and preparedness of school-based mentors in supervising student teachers on teaching practice in Zimbabwe. British Journal of Education, Society and Behavioural Sciences 4(11): 1476-1488.

Wharfe, L. and A. Burrows. 1990. Partnership: A C.N.A.A. perspective on partnership in initial teacher training. London: Cassell.

Zeichner, K. 1992. Rethinking connections between campus courses and field experiences in collegeand university-based teacher education. Journal of Teacher Education 61(1/2): 89-99. 